\title{
Stiffness of Surrounding Soft Tissue of the Donor Site in Patients with Anterior Cruciate Ligament Reconstruction Using Bone-Patellar Tendon-Bone Autograft
}

\author{
S. Demirci', T. I. Yildiz², S. Taş ${ }^{3}$, K. Delioğlư ${ }^{2}$, T. Fırat² ${ }^{2}$ F. Korkusuz ${ }^{4}$, V. Bayrakcı Tunay ${ }^{2}$ \\ 1 Department of Physiotherapy and Rehabilitation, Faculty of Health Sciences, Balıkesir University, Balıkesir, Turkey \\ 2 Department of Atheletes Health, Faculty of Physical Therapy and Rehabilitation, Hacettepe University, Ankara, Turkey \\ 3 Department of Physiotherapy and Rehabilitation, Faculty of Healthy Sciences, Toros University, Mersin, Turkey \\ ${ }^{4}$ Department of Sports Medicine, School of Medicine, Hacettepe University, Ankara, Turkey
}

\section{CORRESPONDING AUTHOR: \\ Serdar Demirci \\ Department of Physiotherapy and \\ Rehabilitation \\ Faculty of Health Sciences \\ Balıkesir University (Cagis Campus) \\ 10145 Balikesir, Turkey \\ E-mail: fztserdar@hotmail.com}

\section{DOI:}

10.32098/mltj.01.2021.03

LEVEL OF EVIDENCE: 3B

\begin{abstract}
SUMMARY
Introduction. While many studies focus on the restoration of muscle strength in the mid-term after anterior cruciate ligament reconstruction (ACLR) with bone-patellar tendon-bone (BTB) autograft, it is not known whether the mechanical properties of the donor site and surrounding soft tissue are restored. The aim of this study was to investigate the mechanical properties of the donor site patellar tendon (PT) and surrounding soft tissues after ACLR with BTB autograft.

Methods. Eight patients with ACLR and 8 age-matched healthy controls were included to the study. Shear Wave Velocity (SWV) of the PT, quadriceps tendon (QT) and vastus medialis obliques (VMO) muscle were performed using an ultrasonography device with linear probe. In addition, the quadriceps femoris $(\mathrm{QF})$ strength was measured with isokinetic dynamometer at $60^{\circ} / \mathrm{sec}$ angular velocity.

Results. There were no differences in the SWV of the PT and VMO muscle between the two groups $(\mathrm{p}>0.05)$. The SWV of the QT was significantly lower in patients with ACLR compared to healthy controls $(\mathrm{p}=0.02)$. There was significantly reduced QF strength on the operated side in patients with ACLR $(p=0.04)$.

Conclusions. The mechanical properties of the PT and VMO are restored in the mid-term after ACLR. However, there may be strength deficit on the donor site QF even after 16 months from the surgery.
\end{abstract}

\section{KEY WORDS}

Anterior cruciate ligament; elastography; patellar tendon; shear wave velocity; stiffness; ultrasound.

\section{INTRODUCTION}

Reconstruction of anterior cruciate ligament (ACL) with autograft is a standard procedure for regaining the stability of the knee joint after ACL injury. Bone-patellar tendonbone (BTB) graft is one of the most frequently used autografts during the surgery $(1,2)$. BTB was observed to be superior in terms of joint stability, extremity function and patient's satisfaction compared to other graft types $(1,2)$. However, complications such as; anterior knee pain, patellar fracture and rupture of the remaining tendon are common- ly observed in patients with ACL reconstruction (ACLR) surgery using BTB (3).

Anterior knee pain can be observed up to 46 to $55 \%$ of the patients undergoing ACLR surgery with BTB $(4,5)$. The healing of the remaining patellar tendon is an important factor that may cause, and its' mechanical properties are thought to be one of the factors that may cause the anterior knee pain. Therefore, some studies have focused to understand the healing process of the donor site patellar tendon (PT) (4-9). Nixon et al. (9) indicated that, the remaining PT 
histologically the same as normal PT after 2 years from the surgery. However, some studies indicated that, the harvested $1 / 3$ mid part of the PT could still be distinguishable from the normal PT more than 2 years after the surgery $(6,10)$. In addition, PT was also found to be wider and thicker and had increased cross-sectional area after harvesting its central 1/3-part compared to normal PT $(6,7)$.

Poor mechanical properties of the harvested PT are thought to be one of the factors that may cause complications and affect the function of the knee. The stiffness and other mechanical properties of the harvested PT decrease in the early stages of post-operative period and restored in time as the tendon's volume increases $(7,11)$. Akkaya et al. (12) assessed the harvested PT with ultrasound and revealed thickening and decreased strain ration on the donor site PT after 2 years from the surgery in contrast to the other studies. Yet, they conducted the measurements only during $30^{\circ}$ of knee flexion. However, there is still little information and conflicting results regarding the mechanical properties of the harvested PT after the surgery.

The healing process of the soft tissues and their mechanical properties can be assessed using different methods. Ultrasonography is one of the most commonly using method for the assessment of the soft tissues $(13,14)$. Sheer Wave Velocity (SWV) is a reliable method for the assessment of the skeletal muscles and tendon units $(14,15)$. The aim this study was to evaluate the mechanical properties of the harvested PT during different knee flexion angles and surrounding soft tissue and the strength of the quadriceps femoris (QF) muscle on patients with ACLR using BTB. The hypothesis of this study was that the stiffness of the harvested PT and surrounding soft tissues of the donor site are restored as the strength of the QF muscle recovers in mid-term after the surgery.

\section{MATERIALS AND METHODS}

\section{Study Design and Participants}

This was an observational study including eight male patients with ACLR surgery with BTB and eight ages matched healthy male subjects. Patellar Tendon, Quadriceps Tendon (QT) and Vastus Medialis Obliques (VMO) stiffness were measured with SWV. Quadriceps femoris strength was measured with isokinetic dynamometer.

The inclusion criteria of the study:

- isolated unilateral arthroscopic ACLR with BTB autograft;

- having passed at least 12 months after the surgery;

- full range of motion in the operated side knee joint;

- no lower extremity problem in healthy group at last 1 -year.
The exclusion criteria of the study:

- ACLR with hamstring tendon autograft or allograft;

- revision of ACLR;

- additional surgery to the ACLR procedure (meniscus and/or cartilage repair, other ligament surgeries);

- complication in the operated knee after the surgery.

All patients were operated with the same surgeon and the same procedure was performed. After the surgery, all patients received the same standard rehabilitation program. The ethical committee of University approved the study with the number of GO 15/816-27. All participants signed the informed-constant form and the experimental procedures were conducted according to the Declaration of Helsinki and as required by the journal (16).

\section{Measurements}

\section{Clinical Assessment}

The demographic characteristics of the participants were recorded prior to the measurements. The International Knee Documented Committee (IKDC) score (ICC 0.94) was used to evaluate the knee functions of the patients (17). The questionnaire contains 10 items related to knee-related symptoms, sports, and functional activities. The score ranges from 0 to 100 , and the higher score indicates better knee function.

\section{Ultrasonographic Measurements}

The ultrasonographic measurements of the VMO muscle, PT and QT were performed with the ACUSON S3000 device with using 9L4 (4-9 MHz) linear-array ultrasound probe (Siemens Medical Solution, Mountain View, CA, USA). Prior to the testing, participants rested for 5 minutes in a seated position to ensure the elastic modulus of the patellar tendon was evaluated at resting status. The room temperature was controlled at $25^{\circ} \mathrm{C}$.

The VMO muscle was assessed in long sitting position while hips were semi-flexed and knees were fully extended (figure 1). The probe was placed approximately 10 centimeters $(\mathrm{cm})$ proximal to the apex of patella in the direction of the muscle fibers. The elastographic features were obtained from the plumpest section of the muscle (18).

The elastographic features of the PT and QT were obtained in the supine lying position while both knee were flexed $30^{\circ}$ (19). The US probe was placed to the mid-point of the PT (between $1 \mathrm{~cm}$ distal of the patellar bone-tendon junction and $1 \mathrm{~cm}$ proximal of bone-tendon junction of tibia) (figure 1). For the SWV measurements of the QT, the US probe was placed on the area between the musculotendinous junction of quadriceps tendon and the proximal part of the patella 
(figure 1). The transducer was stationed on the skin, with a light pressure on top of a generous amount of coupling gel, perpendicularly on the skin's surface.

Virtual Touch Imaging and Quantification ${ }^{\circledR}$ (VTIQ) software was used to assess the SWV (Siemens Medical Solution, Mountain View, CA, USA) of the PT, QT, VMO. After taking the VTIQ image, range of images (ROIs), which are $0.5 \times 0.5 \mathrm{~mm}$ boxes, were placed along the direction of the muscle and tendon fibers line. Average of used ROIs were used to calculate the SWV of assessed VTIQ image. The higher value of the SWV indicates more stiff tissue. The SWV measurements were determined at least 20s breaks, via average of three measurements, consecutively. All measurements were performed bilaterally on both patients and healthy participants.

\section{Muscle Strength Assessment}

QF muscle strength was measured with isokinetic dynamometer (IsoMed ${ }^{\circledR} 2000$ D \& R GmbH, Germany). Prior to testing, participants warmed-up for 5 minutes

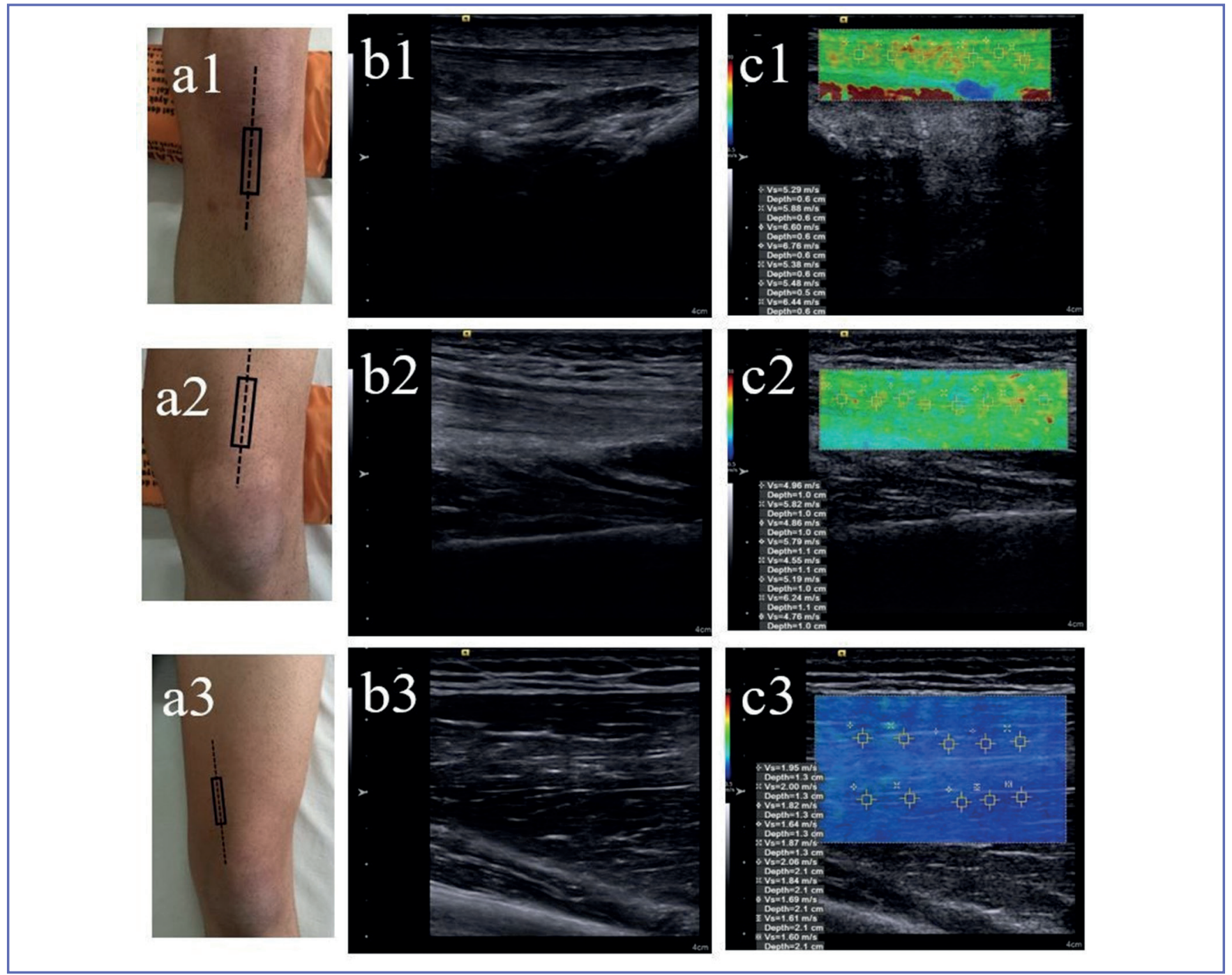

Figure 1. Probe location and ultrasound imaging measurements. (a1) probe position of the patellar tendon, (a2) quadriceps tendon, and (a3) vastus medialis muscle at stiffness measurements; (b1) 2-dimensional ultrasound image of the patellar tendon, (b2) quadriceps tendon, and (b3) vastus medialis muscle at stiffness measurements; (c1) color map images of the patellar tendon, (c2) quadriceps tendon, and (c3) vastus medialis muscle at stiffness measurements. Regions of interest were placed, and corresponding shear wave velocity $(\mathrm{m} / \mathrm{sec})$ was recorded. Red-coded areas represent the highest stiffness, blue-coded areas represent the lowest stiffness, and green-coded areas represent intermediate stiffness. 
on an electronic cycle ergometer. During the measurement, patients were seated on the isokinetic dynamometer with knees and hips flexed at $90^{\circ}$ and they were fixed to the device with straps from both shoulders and belly. The rotation center of the knee joint was aligned to the center of the dynamometer. The lever arm of the device was placed at just proximal to the lateral malleoli. The test was executed between $0^{\circ}$ and $90^{\circ}$ of knee flexion-extension range of motion. In order to familiarize to the testing procedure, participants performed 3 repetitions of knee flexion-extension with the isokinetic device prior to the test. During the testing procedure, participants performed 5 repetitions of knee flexion and extension at $60 \%$ sec angular velocity at their maximum strength. Both knees were tested and the testing order was determined randomly.

\section{Statistical Analysis}

All data were analyzed with the statistical package for social sciences (SPSS Version 21, Chicago, IL, USA). The demographic characteristics of the participants were analyzed with the independent sample $t$ test. Mann Whitney-U Test was used for the comparison of the mechanical properties of the PT, QT and VMO and, the QF strength between the two groups. The mechanical properties of the PT, QT and VMO, and the QF strength between the dominant and the non-dominant of the patients with the ACLR were analyzed with Wilcoxon Test.

\section{RESULTS}

The demographics characteristics of the participants on both groups were similar (table I). The average post-operative duration of the patients was $15.6 \pm 2.7$ months (ranging from 13 to 20 months). The pain intensity of the patients was $0.7 \pm 1.1$.

QF strength in operated side was lower than non-operated side in patients with ACLR $(\mathrm{p}=0.04)$. SWV of the QT was similar on the dominant and non-dominant sides in patients with ACLR whereas it was lower than that of the control group $(\mathrm{p}=0.02)$. There was no difference on the SWV of the PT, and VMO muscle between the dominant sides of the healthy participants and the operated sides of the patients with ACLR ( $p>0.05$ ). There was also no difference on the SWV of the PT, QT and VMO muscle between the operated and the non-operated side on patients with ACLR ( $p$ > 0.05) (table II).

Table I. The demographics characteristics of the subjects.

\begin{tabular}{|c|c|c|c|}
\hline & $\begin{array}{c}\text { Patient }(n=8) \\
\text { Mean } \pm \text { SD }\end{array}$ & $\begin{array}{c}\text { Healthy Control }(\mathrm{n}=8) \\
\text { Mean } \pm \text { SD }\end{array}$ & $\mathbf{p}$ \\
\hline Age (years) & $27.7 \pm 6.6$ & $27.8 \pm 4.7$ & 0.875 \\
\hline Body mass index $\left(\mathrm{kg} / \mathrm{m}^{2}\right)$ & $26.6 \pm 2.7$ & $24.1 \pm 1.8$ & 0.090 \\
\hline Body fat percentage ( $\%)$ & $21.5 \pm 5.1$ & $18.0 \pm 3.02$ & 0.115 \\
\hline Time since operation (months) & $15.6 \pm 2.7$ & -- & -- \\
\hline IKDC & $85.3 \pm 8.5$ & -- & -- \\
\hline
\end{tabular}

SD: standard deviation, IKDC: international knee documentation committee.

Table II. Strength and stiffness of the subjects.

\begin{tabular}{|c|c|c|c|c|c|c|c|}
\hline & \multicolumn{2}{|c|}{$\begin{array}{c}\text { Patient }(n=8) \\
\text { Mean } \pm \text { SD }\end{array}$} & \multirow{2}{*}{$\mathbf{p}_{1}$} & \multicolumn{2}{|c|}{$\begin{array}{c}\text { Healthy Control }(n=8) \\
\text { Mean } \pm \text { SD }\end{array}$} & \multirow{2}{*}{$\mathbf{p}_{2}$} & \multirow[t]{2}{*}{$\mathbf{p}_{3}$} \\
\hline & Operated & Non-operated & & Dominant & Non-dominant & & \\
\hline QF strength $60^{\circ} / \mathrm{sec}(\mathrm{Nm} / \mathrm{kg})$ & $2.30 \pm 0.50$ & $2.70 \pm 0.5$ & $0.04^{*}$ & $2.40 \pm 0.3$ & $2.3 \pm 0.20$ & 0.40 & 0.60 \\
\hline PT stiffness $(\mathrm{m} / \mathrm{sec})$ & $7.42 \pm 1.76$ & $7.10 \pm 1.26$ & 0.40 & $7.58 \pm 1.65$ & $7.37 \pm 1.5$ & 0.8 & 0.80 \\
\hline QT stiffness $(\mathrm{m} / \mathrm{sec})$ & $4.30 \pm 0.38$ & $4.32 \pm 0.49$ & $>0.05$ & $4.75 \pm 0.30$ & $4.76 \pm 0.5$ & $>0.05$ & $0.02^{*}$ \\
\hline PT $90^{\circ}$ stiffness $(\mathrm{m} / \mathrm{sec})$ & $9.30 \pm 0.60$ & $9.70 \pm 0.10$ & 0.20 & $9.10 \pm 0.80$ & $8.80 \pm 1.4$ & 0.50 & 0.50 \\
\hline VMO muscle stiffness $(\mathrm{m} / \mathrm{sec})$ & $2.07 \pm 0.20$ & $2.20 \pm 0.30$ & 0.20 & $2.02 \pm 0.13$ & $2.08 \pm 0.2$ & 0.50 & 0.40 \\
\hline
\end{tabular}

$\mathrm{p}_{1}$ : intra group comparison of patient, $\mathrm{p}_{2}$ : intra group comparison of healthy control, $\mathrm{p}_{3}$ : inter group comparison, SD: standard deviation, *p $<0.05$. 


\section{DISCUSSION}

The study was aimed to investigate the mechanical properties of the PT, QT and VMO on patients with ACLR compared to healthy control. The most important finding of the study is that the elastographic properties of the soft tissues on the donor site are restored in the mid-term after ACLR surgery. The donor site mechanical properties of the PT and VMO were similar on patients with ACLR and the dominant side of the healthy participants. These findings partly support our hypothesis that the mechanical properties of the surrounding soft tissues of the knee recover in mid-term. However, QT stiffness on both sides on patients with ACLR was lower than the healthy participants. In addition, there still strength deficit on the QF on patients with ACLR after 16 months from the surgery. Our study is important in that, it was the first study comparing the elastographic properties of PT, QT and VMO on patients with ACLR with the healthy participants.

After the surgery, a regeneration process starts on the donor site of PT. Studies revealed that, the collagen composition of the PT increases rapidly starting from the early stages of post-operative period $(6,22)$. The gap in the PT is closed with the collagen tissue between 8 to 24 months after surgery $(9,22)$. In parallel with the healing process, the mechanical properties of the healing tissue also recover. It was found that, the stiffness of the PT decreases in the early postoperative periods, and later it starts to increase as the cross-sectional area of the tendon increases (7). In the long term after the ACL surgery the surgery, the PT becomes more thicker and stiffer compared to non-operated side $(12,23)$. We also had similar results in that, the stiffness of the PT on the donor site was similar compared to non-operated side and healthy participants in the mid-term after the surgery. It may be thought that as the PT becomes more thicker the stiffness starts to restore starting from the mid-term after the surgery. In addition, donor site PT had similar response to the stretching compared to normal tendon. The stiffness of the normal PT was found to increases with the increased knee flexion angle (24). Current study found that the stiffness of the PT on both the operated and the non-operated sides was increased as the knee flexion angle is increased which was similar to the healthy participants.

The interesting result of our study was that the stiffness of the QT on both sides on patients with ACLR was lower than that of the dominant side of the healthy participants. The stiffness of a tendon increases with exercise and repetitive loading and decrees with inactivity (25). Patients with ACLR did not able to perform high intensity exercise until post-operative 5 months. Patients with ACLR were rela- tively inactive compared to healthy participants. Therefore, it may be indicated that, the decrease in the QT tendon stiffness may be due to the inactivity of the patients with ACLR during the early stages of the post-operative period compared to the healthy controls.

There were also similar mechanical properties in the donor site VMO compared to the non-operated side and the healthy controls. Studies reported that muscle strength and stiffness of the muscles are correlated. Patients with ACLR had lower QF strength on the donor site, yet it was not clear whether this deficit was due to the VMO. Hence, it is debatable that similar stiffness in the VMO is correlated with the strength of the muscle.

There was a strength deficit in QF muscle on the operated side compared to the non-operated side on patients with ACLR. The QF strength deficit is an important contributor to the ACL injury (26). Athletes with a greater lower extremity strength deficit have decreased functional capacity and are more prone to ACL injury (27-29). The graft choice has a major influence on the lower extremity strength deficits after ACLR surgery. Patients with ACLR using BTB autograft was reported to have decreased QF strength after 24 months from the surgery (30). The literature supports our findings that there was still QF weakness on patients with ACLR after 16 months from surgery. While the mean IKDC score in patients was below the criteria for returning to sports 1 year after surgery, it was very close to the normative data of healthy individuals in the same age group (31). It can be said that low IKDC score is associated with quadriceps muscle strength deficit.

There were some limitations in the current study. First there were only 8 patients with ACLR using BTB autograft. Most of the patients in our clinic were operated using hamstring tendon autograft and they were excluded as we wanted to investigate the mechanical properties of the harvested PT. Second, only male patients were included to the study. Therefore, our results cannot be generalized to all populations. Lastly, we used ultrasonography to measure the mechanical properties of the soft tissues and our patients were passive during the measurements. Yet, the stiffness can also be assessed while patients are active.

\section{CONCLUSIONS}

In conclusion, the mechanical properties of the PT and VMO are restored in the mid-term after ACLR surgery. However, there may still be QF strength deficit on the donor site. Therefore, the strength training needs to be continued after 1.5 years from the surgery. 


\section{Main points}

- The mechanical properties of the donor site soft tissues are restored in mid-term after ACL reconstruction.

- There may still be strength deficits in the operated knee muscles.

- Poorer mechanical properties might be one of reasons for anterior knee pain during the early stages of the post-operative period.

\section{FUNDINGS}

There was no funding of the study.

\section{CONFLICT OF INTERESTS}

The authors declare that they have no conflict of interests.

\section{REFERENCES}

1. Schuette HB, Kraeutler MJ, Houck DA, McCarty EC. Bonepatellar tendon-bone versus hamstring tendon autografts for primary anterior cruciate ligament reconstruction: a systematic review of overlapping meta-analyses. Orthop J Sports Med 2017;5(11):2325967117736484.

2. Aune AK, Holm I, Risberg MA, Jensen HK, Steen H. Fourstrand hamstring tendon autograft compared with patellar tendon-bone autograft for anterior cruciate ligament reconstruction: a randomized study with two-year follow-up. Am J Sports Med 2001;29(6):722-8.

3. Hardy A, Casabianca L, Andrieu K, Baverel L, Noailles T. Complications following harvesting of patellar tendon or hamstring tendon grafts for anterior cruciate ligament reconstruction: systematic review of literature. Orthop Traumatol Surg Res 2017;103(8):S245-S8.

4. Kleipool AE, van Loon T, Marti RK. Pain after use of the central third of the patellar tendon for cruciate ligament reconstruction: 33 patients followed 2-3 years. Acta Orthop Scand 1994;65(1):62-6.

5. Breitfuss H, Fröhlich R, Povacz P, Resch H, Wicker A. The tendon defect after anterior cruciate ligament reconstruction using the midthird patellar tendon-a problem for the patellofemoral joint? Knee Surg Sports Traumatol Arthrosc1996;3(4):194-8.

6. Kartus J, Movin T, Papadogiannakis N, Christensen LR, Lindahl S, Karlsson J. A radiographic and histologic evaluation of the patellar tendon after harvesting its central third. Am J Sports Med 2000;28(2):218-26.

7. Reeves ND, Maganaris CN, Maffulli N, Rittweger J. Human patellar tendon stiffness is restored following graft harvest for anterior cruciate ligament surgery. J Biomech 2009;42(7):797-803.

8. Yazdanshenas H, Madadi F, Madadi F, Washington III ER, Jones K, Shamie AN. Patellar tendon donor-site healing during six and twelve months after anterior cruciate ligament reconstruction. J Orthop 2015;12(4):179-83.
9. Nixon RG, SeGall GK, Sax SL, Cain TE, Tullos HS. Reconstitution of the patellar tendon donor site after graft harvest. Clin Orthop Relat Res 1995;317:162-71.

10. Svensson M, Kartus J, Christensen LR, Movin T, Papadogiannakis N, Karlsson J. A long-term serial histological evaluation of the patellar tendon in humans after harvesting its central third. Knee Surg Sports Traumatol Arthrosc 2005;13(5):398-404.

11. Tohyama H, Yasuda K, Kitamura Y, Yamamoto E, Hayashi $\mathrm{K}$. The changes in mechanical properties of regenerated and residual tissues in the patellar tendon after removal of its central portion. Clin Biomech 2003;18(8):765-72.

12. Akkaya S, Akkaya N, Agladıoglu K, Gungor HR, Ok N, Özçakar L. Real-time elastography of patellar tendon in patients with auto-graft bone-tendon-bone anterior cruciate ligament reconstruction. Arch Orthop Trauma Surg 2016;136(6):837-42.

13. Fusini F, Langella F, Busilacchi A, et al. Real-time sonoelastography: principles and clinical applications in tendon disorders. A systematic review. MLTJ 2017;7(3):467.

14. Taş S, Onur MR, Yilmaz S, Soylu AR, Korkusuz F. Shear wave elastography is a reliable and repeatable method for measuring the elastic modulus of the rectus femoris muscle and patellar tendon. J Ultrasound Med 2017;36(3):565-70.

15. Pang BS, Ying M. Sonographic measurement of achilles tendons in asymptomatic subjects: variation with age, body height, and dominance of ankle. J Ultrasound Med 2006;25(10):1291-6.

16. Padulo J, Oliva F, Frizziero A, Maffulli N. Muscles, Ligaments and Tendons Journal-Basic principles and recommendations in clinical and field Science Research: 2016 Update. MLTJ 2016;6(1):1.

17. Irrgang JJ, Anderson AF, Boland AL, et al. Responsiveness of the international knee documentation committee subjective knee form. Am J Sports Med 2006;34(10):1567-73.

18. Botanlioglu H, Kantarci F, Kaynak G, et al. Shear wave elastography properties of vastus lateralis and vastus medialis obliquus muscles in normal subjects and female patients with patellofemoral pain syndrome. Skeletal Radiol 2013;42(5):659-66.

19. Ozcan ANS, Tan S, Tangal NG, et al. Real-time sonoelastography of the patellar and quadriceps tendons: pattern description in profesional athletes and healthy volunteers. Med Ultrason 2016;18(3):299-304.

20. Lewek M, Rudolph K, Axe M, Snyder-Mackler L. The effect of insufficient quadriceps strength on gait after anterior cruciate ligament reconstruction. Clin Biomech 2002;17(1):56-63.

21. Bisciotti GN, Quaglia A, Belli A, Carimati G, Volpi P. Return to sports after ACL reconstruction: a new functional test protocol. MLTJ 2016;6(4):499.

22. Berg EE. Intrinsic healing of a patellar tendon donor site defect after anterior cruciate ligament reconstruction. Clin Orthop Relat Res 1992(278):160-3.

23. Gulledge CM, Baumer TG, Juliano L, et al. Shear wave elastography of the healing human patellar tendon following ACL reconstruction. Knee 2019;26(2):347-54.

24. Coombes BK, Ziegenfuss B, David M, et al. Heterogeneity of passive elastic properties within the quadriceps femoris muscle-tendon unit. Eur J Appl Physiol 2018;118(1):213-21.

25. Magnusson SP, Narici MV, Maganaris CN, Kjaer M. Human tendon behaviour and adaptation, in vivo. J Physiol 2008;586(1):71-81. 
26. Nagelli CV, Hewett TE. Should return to sport be delayed until 2 years after anterior cruciate ligament reconstruction? Biological and functional considerations. Sports Med 2017;47(2):221-32.

27. Schmitt LC, Paterno MV, Hewett TE. The impact of quadriceps femoris strength asymmetry on functional performance at return to sport following anterior cruciate ligament reconstruction. J Orthop Sports Phys Ther 2012;42(9):750-9.

28. Schmitt LC, Paterno MV, Ford KR, Myer GD, Hewett TE. Strength asymmetry and landing mechanics at return to sport after ACL reconstruction. Med Sci Sports Exerc 2015;47(7):1426.

29. Maffulli N, Oliva F. Coper Classification Early After ACL Rupture Changes With Progressive Neuromus- cular and Strength Training and Is Associated With 2-Year Success: Letter to the Editor. Am J Sports Med 2019;47(11):NP64-NP5.

30. Xergia SA, McClelland JA, Kvist J, Vasiliadis HS, Georgoulis AD. The influence of graft choice on isokinetic muscle strength 4-24 months after anterior cruciate ligament reconstruction. Knee Surg Sports Traumatol Arthrosc 2011;19(5):768-80.

31. Logerstedt D, Di Stasi S, Grindem H, et al. Self-reported knee function can identify athletes who fail return-to-activity criteria up to 1 year after anterior cruciate ligament reconstruction: a delaware-oslo ACL cohort study. J Orthop Sports Phys Ther 2014;44(12):914-23. 